\title{
“A Study ToAssess The Effectiveness Of Aromatherapy On Post Operative Pain Among Patients Undergone Abdominal Surgery
}

${ }^{*}$ Ms.MintuJoshua **Dr.Renuka.K \& ${ }^{* * *}$ D.S.HannahAswini

\begin{abstract}
:
Objective- To evaluate the effectiveness of aromatherapy on post-operative patients in experimental and control group during pretest and post test Method- Quasi Experimental design with one group pre-test and post-test was adapted for the study. Result- The findings revealed that the obtained $t$ value 21.938 was significant at $p<0.05$ level. Aromatherapy was effective in reducing the post operative pain among patients who had undergone abdominal surgery. Conclusion :Administration of aromatherapy to the hospital pain management protocol enhanced the control of pain and relaxation of the clients .hence aromatherapy can be used as safe and inexpensive adjunct to conventional medicine
\end{abstract}

Keywords: Effectiveness, abdominal surgery patients, post operative pain and aromatherapy

\section{INTRODUCTION}

Pain is the major problem that causes suffering and reduces the quality of life. The financial impact of pain is staggering. Pain control is a contemporary issue that is of immense importance due to devastating and humanizing effects it can have upon individual. Aromatherapy is a complementary therapy for pain management. It is thought to enhance the parasympathetic response through the effect of smell, touch and encountering relaxation at a deep level.

\section{OBJECTIVE:}

1. To assess the level of post operative pain among post operative patients in experimental and control group during pre test
2. To evaluate the effectiveness of aroma therapy on postoperative pain among patients in experimental and control group during post test

3. To assess the level of post operative pain among post operative patients in control group during post test

4. To determine the association between level of post operative pain and selected demographic variables of post operative patients

\section{RESEARCH HYPOTHESIS}

$\mathbf{H}_{1}$ : There will be significant difference in the between the the effectiveness of aroma therapy on postoperative pain among patients in experimental and control group. 
$\mathbf{H}_{2}$ : There will be significant association between level of post operative pain and selected demographic variables of post operative patients in of the experimental group with their selected demographic variables.

\section{METHODOLOGY}

\section{RESEARCH APPROACH}

The research approach used for the study was Quantitative research approach

\section{Research design}

Experimental design

\begin{tabular}{|l|l|l|l|}
\hline Group & $\begin{array}{l}\text { Pre } \\
\text { test }\end{array}$ & $\begin{array}{l}\text { Inter } \\
\text { vention }\end{array}$ & $\begin{array}{l}\text { Post } \\
\text { test }\end{array}$ \\
\hline $\begin{array}{l}\text { Exp } \\
\text { group }\end{array}$ & $\mathrm{O}_{1}$ & $\mathrm{X}$ & $\mathrm{O}_{2}$ \\
\hline $\begin{array}{l}\text { Control } \\
\text { group }\end{array}$ & $\mathrm{O}_{1}$ & - & $\mathrm{O}_{2}$ \\
\hline
\end{tabular}

\section{STUDY SETTING}

The study was conducted at post operative ward and surgical wards of MGMC\&RI Puducherry.

\section{POPULATION}

The population included in the study was patients who have undergone minor and major abdominal surgery

\section{SAMPLE SIZE}

The sample for the study comprised of 60 patients who have undergone minor and major abdominal surgery

\section{SAMPLING TECHNIQUE}

The sampling procedure used for this study was Simple random sampling technique.

\section{Criteria For Sample Selection \\ Inclusion Criteria}

$>$ Post operative patients for aperiod of first two post operative days

$>$ Patients willing to receive aromatherapy
$>$ Post operative patients more than 20 years

$>$ Both sexes

\section{EXCLUSION CRITERIA}

$>$ Critically ill postoperative patients

$>$ Patients who are having respiratory disorders

$>$ Pregnant and breast feeding women

Table 1:mean, standard deviation ,mean difference and " $t$ "value of poat test pain level among patients undergone abdominal surgery patients in experimental and control group

\begin{tabular}{|l|l|l|l|l|}
\hline Group & Mean & $S D$ & $M D$ & " $t$ "Value \\
\hline 1.Exp & & & & \\
Pre Test & 8 & 1.04 & 5 & 21.938 \\
Post Test & 3 & 1.29 & & \\
2.Control & & & & \\
Pre Test & 8 & 1.09 & 3 & 19.65 \\
Post Test & 5 & 1.35 & & \\
\hline
\end{tabular}

The Mean Pain Level 3 and SD OF

1.29 of experimental group was significantly differing from mean pain level 5 and SD 1.35 of control group .it was referred that there was significant difference between experimental and control group during post test. The mean pain level of experimental group 3 shows that, significant reduction of pain level was more among experimental group compared to control group.it was inferred that aromatherapy was more effective than the routine pain management

\section{MAJOR FINDINGS}

The findings revealed that the obtained $t$ value 21.938 was significant at $\mathrm{p}<0.05$ level. 
Aromatherapy was effective in reducing the post operative pain among patients who had undergone abdominal surgery.

\section{CONCLUSION}

The main conclusion of the present study is that majority of the post operative patients $25(83.33 \%$ ) in the experimental group and $25(83.33 \%)$ in the control group had severe pain during pre test during post test majority of the patients $22(73.33 \%$ )in the control group had moderate pain table 1 shows that the aromatherapy was more effective than routine pain management which revealed that aroma therapy is effective in reducing post operative pain .it helps to reduce the doses of analgesics and their side effects .administration of aromatherapy as complementary therapy to the hospital pain management protocol enhanced the control of pain .hence aromatherapy can be used as safe and inexpensive ,adjuvant to conventional medicine

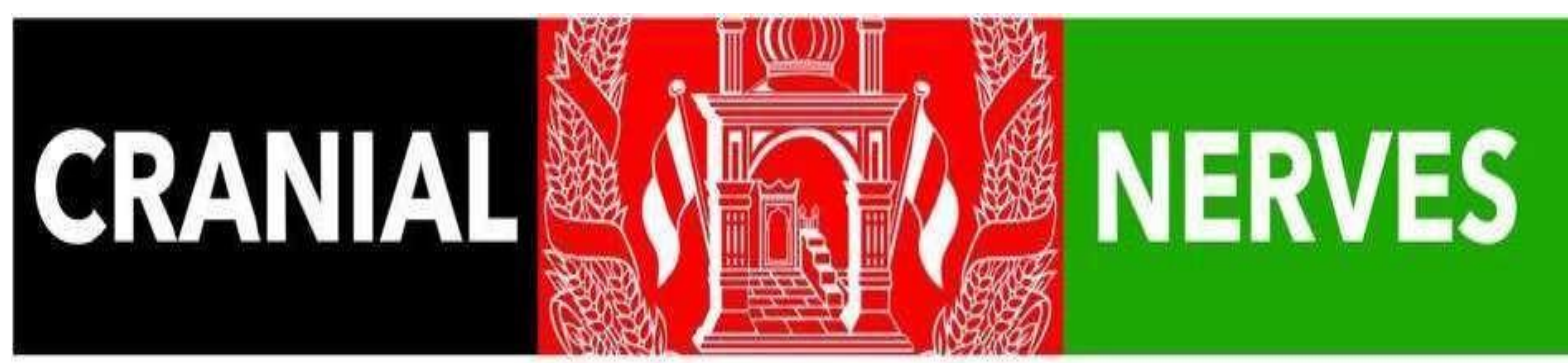

$\begin{array}{llll}\underline{\text { On }} & \text { Olfactory (CN*I) } & \text { Sensory } & \text { Some } \\ \text { Occasion } & \text { Optic (CN II) } & \text { Sensory } & \text { Say } \\ \text { Our } & \text { Oculomotor (CN III) } & \text { Motor } & \text { Marry } \\ \text { Trusty } & \text { Trochlear (CN IV) } & \text { Motor } & \text { Money } \\ \text { Truck } & \text { Trigeminal (CN V) } & \text { Both** } & \underline{\text { But }} \\ \text { Acts } & \text { Abducens (CN VI) } & \text { Motor } & \underline{\text { My }} \\ \text { Funny } & \text { Facial (CN VII) } & \text { Both } & \text { Brother } \\ \text { Very } & \text { Vestibulocochlear (CN VIII) } & \text { Sensory } & \text { Says } \\ \text { Good } & \text { Glossopharyngeal (CN IX) } & \text { Both } & \text { Big } \\ \text { Vehicle } & \text { Vagus (CN X) } & \text { Both } & \text { Brains } \\ \text { Any } & \text { Accessory (CN XI) } & \text { Motor } & \text { Matter } \\ \text { How } & \text { Hypoglossal (CN XII) } & \text { Motor } & \text { More }\end{array}$

